\title{
Editorial
}

\section{Using of Fresh Cadaveric Cow Brain in the Microsurgical Training Model for Sulcal-Cisternal and Fissural Dissection}

In the present study, authors detail their experience of microneurosurgical dissections in ten fresh cadaveric cow brains. ${ }^{[1]}$ I congratulate the authors for bringing up this study as not many articles published in India has touched the subject which got implications in microneurosurgical training.

Correct microsurgical techniques are the cornerstone to exposure of almost all deep-seated brain lesions and needless to say to achieve a good outcome. A laboratory training facility with dissection on the fresh brain will help the neurosurgery resident to gain hands-on experience and skills on the basic dissection and drilling techniques, before the operative room exposure. Dissection of fresh brain tissue got its distinct advantages over the ones with formalin-fixed with respect to texture, vascular friability, and ease of identification of iatrogenic damage on dissection. Use of fresh cadaveric cow brain is an economical and viable option considering the ease of availability and less legal and ethical issues involved. Keeping in mind the differences in human and cow brain as discussed in the article, it stands out as an excellent alternative to both fresh as well as the formalin-fixed human brain, from a practical perspective. ${ }^{[1]}$ In a center with advanced facilities, it can also be used in the training and research into other areas of neurosurgery such as neuroendoscopy, base of skull surgery, functional neurosurgery, and vascular neurosurgery.

The dissecting surgeon should exercise the necessary caution to operate meticulously with due care as if operating on a live brain to gain the maximum advantage. The same professional attitude also will give the due respect to the animal brain which it deserves. Precautions, adequate personal protection as well as careful administration of institutional protocols are necessary to prevent the spread of animal diseases.

Raghunath Avanali

Department of Epilepsy Neurosurgery, University of Calgary, Calgary, AB, Canada

Address for correspondence: Dr. Raghunath Avanali, University of Calgary, Calgary, AB, Canada. E-mail: raghunimhans@yahoo.co.in

\section{REFERENCE}

1. Gökyar A, Cokluk C. Using of fresh cadaveric cow brain in the microsurgical training model for sulcal-cisternal and fissural dissection. J Neurosci Rural Pract 2017;9:26-9.

This is an open access article distributed under the terms of the Creative Commons Attribution-NonCommercial-ShareAlike 3.0 License, which allows others to remix, tweak, and build upon the work non-commercially, as long as the author is credited and the new creations are licensed under the identical terms.

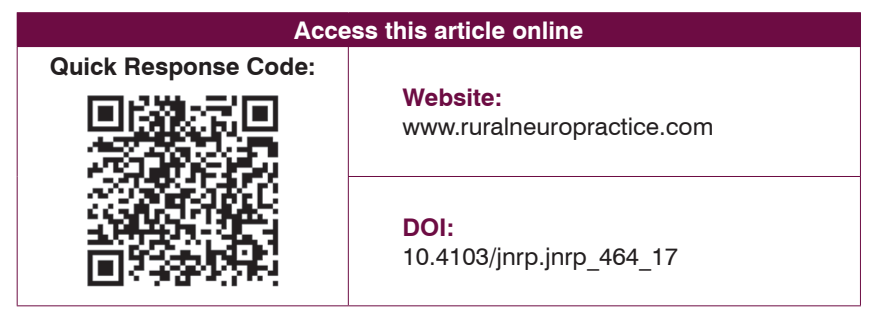

How to cite this article: Avanali R. Using of fresh cadaveric cow brain in the microsurgical training model for sulcal-cisternal and fissural dissection. J Neurosci Rural Pract 2018;9:5. 